\title{
Neuroembryology Education for Paediatric Neurology and Neuropathology Trainees in Canada*
}

\author{
Harvey B. Sarnat
}

Can. J. Neurol. Sci. 2010; 37: 105-109

\section{Development is the essence of paediatrics; embryology is the essence of development.}

In every organ system of the body, a comprehension of development and change with growth and maturation are factors distinguishing the paediatrician and paediatric subspecialists from their counterparts in adult medicine. Embryology or developmental anatomy is of greater importance to neurologists than to specialists of most other organ systems because of the uniqueness of every neuron, by contrast with pulmonary epithelial cells or hepatocytes, for example, that all have identical functions. Some scientific purists object to the use of the term "neuroembryology" beyond the embryonic period proper, the first six postconceptional weeks in the human. Nevertheless, the traditional use of the term since the 19th century applies it not only to early ontogenesis but to the fetal period until birth.

Paediatric neurology residency training programmes in Canada have experienced a progressive reduction in the teaching of both neuroembryology and neuropathology over the past two decades, an educational dilution that has impeded a full understanding of many neurological disorders of infants and children, foremost the malformations of the central nervous system (CNS), including underlying genetic and metabolic disorders. We learn ages of acquisition of various developmental skills, but do not often enough pose the question of why a child sits without support only at six months or walks unassisted at a year, in terms of anatomical and physiological maturation. Most contemporary trainees can readily diagnose, from magnetic resonance imaging (MRI), agenesis of the corpus callosum, cerebellar hypoplasia and mesial temporal sclerosis, but how many senior residents can then discuss the embryonic development of these major structures of the brain, the corpus callosum, cerebellum and hippocampus? How many can define the ontogeny of much smaller but essential structures as the nucleus/fasciculus solitarius (central respiratory centre), nucleus ambiguus (deglutition centre), reticular activating system, locus coeruleus, nucleus accumbens or the nucleus of Darkschewitsch in the periaqueductal grey matter? The fault of this educational deficiency lies not primarily with the residents, who in general are bright, motivated and eager to learn, but with the design of their five-year curriculum that largely ignores or marginalizes the whole topic of neuroembryology.

\section{Historical Perspective}

Trainees in any medical specialty need to be familiar with the history of their own discipline, especially in their own country, to enable them to enhance it with future contributions, just as children need to learn Canadian history to understand the character and principles upon which their country is founded.

An absence of structured teaching of neuroembryology was not always the case, though the exact content of neuroembryology teaching at each institution in training programmes of previous decades is not well documented. The discipline of paediatric neurology and the parallel development of its specialty residency programmes evolved in Canada in the 1960s and 1970s under the leadership of such visionaries as John Stobo Pritchard and later Bill Logan in Toronto, Henry Dunn in Vancouver, Preston Robb, Gordon Watters in Montréal, John Tibbles and Peter and Carol Camfield in Halifax, Peter Humphreys in Ottawa and Robert Haslam in Calgary and Toronto. Though none of these early training directors would identify themselves as neuroembyologists, they all showed interest and recognized a need to facilitate this education. They were assisted in this venture by a group of internationally recognized Canadian paediatric neuropathologists that included Margaret Norman in Vancouver, Larry Becker in Toronto and Yvès Robataille and Kathleen Villemure in Montréal. The field of expertise was later strengthened further by Roland Auer in Calgary and Marc Del Bigio in Winnipeg. Beginning in the early 1990s and extending to the present day, there occurred a slow, steady erosion in instruction in neuroembryology within the training parametres of paediatric neurologists in Canada, coincidental with a desire to provide time,

*The concept of a standardized Canadian neuroembryology course is endorsed by the Canadian Association of Neuropathologists and by the Canadian Association of Child Neurology

From the Departments of Paediatrics, Pathology and Laboratory Medicine and Clinical Neurosciences, University of Calgary Faculty of Medicine, Alberta Children's Hospital, Calgary, Alberta, Canada.

Received May 11, 2009. Final Revisions Submitted July 20, 2009.

Correspondence to: H.B. Sarnat, Departments of Paediatrics, Pathology and Laboratory Medicine and Clinical Neurosciences, University of Calgary Faculty of Medicine, Alberta Children's Hospital, 2888 Shaganappi Road SW, Calgary, Alberta T3B 6A8. 
but without lengthening the overall residency period, to other disciplines rapidly growing in importance, such as EEG monitoring, neuroimaging and the molecular genetics of neurological diseases.

\section{Reasons For A Decline In Structured Teaching Of Developmental neuroanatomy In Canadian Paediatric Neurology Residency Programmes}

1) A perception that neuroembryology is an old-fashioned, static discipline of the late 19th and early 20th centuries, lacking parallel innovative dynamism to recent advances in EEG, neuroimaging and molecular genetics. The several excellent available texts and atlases of the human fetal brain at progressive stages of development with advancing gestational age $^{1-6}$ seldom are used in contemporary paediatric neurology training programmes. Part of the problem is the orientation of the authors of such atlases, most of whom are basic scientists without medical backgrounds who cannot be expected to identify the relevance of clinical correlations with development, for example of the nucleus solitarius with apnea of prematurity. Monographs on developmental malformations include by necessity a great deal of information on normal development, and my own book of $1992^{7}$ and that of Margaret Norman of $1995^{8}$ were the last texts of the classical period of neuroembryology, just at the onset of the explosion of new molecular genetic data that changed whole concepts on the programming of brain development. Traditional contemporary textbooks of neuropathology, and even those limited in scope to paediatric neuropathology, include minimal information on normal development and are not systematically presented as a study of neuroembryology.

In many of the available gross and histological atlases of the human fetal brain by nonphysicians, the orientation of brain sections corresponds neither to standard cuts used by neuropathologists nor to standard imaging cuts used by radiologists, hence the sections appear unfamiliar and can be readily understood only by those with a tridimensional knowledge of neuroanatomy in the immature brain possessed by few of our trainees or paediatric neurology faculty.

Another problem with these current atlases is that they show only macroscopic and microscopic morphogenesis without the wealth of immunocytochemical data now available relating morphology to such features as regional metabolic development in the brain, maturation of individual neurons, synaptogenesis and distribution of developing neurotransmitter systems and membrane receptors. The only specialized feature shown in some of these texts is the spatial and temporal development of myelination of major axonal pathways ${ }^{9,10}$. At the microscopic level, much more data are available than the simple demonstration by staining of tissue sections with the haematoxylin-eosin (H\&E), Nissl stains and luxol fast blue for myelin. Important anatomical structures of the fetal brain not seen by conventional histological stains, such a radial glial fibres, are well demonstrated by vimentin. Histochemical stains demonstrate mitochondrial oxidative enzyme activities during neuronal development. The genetic gradients along the axes of the neural tube ${ }^{11,12}$ and mapping of synaptogenesis of the developing brain ${ }^{13}$ are features of modern neuroembryology not shown in traditional textbooks. These few examples illustrate that developmental neuroanatomy can be as dynamic as molecular genetics or novel advances in neuroimaging. Few of our residents are aware of these relatively recent data, much less are able to correlate them clinically with functional maturation.

2) Paucity of faculty qualified to teach neuroembryology. The specialists most qualified to teach developmental neuroanatomy by training and experience are paediatric neuropathologists. Such specialists are sparse in all developed countries, Canada amongst them. Of the 16 medical schools in Canada, only four have a dedicated paediatric neuropathologist on faculty. The ratio is even worse in the U.S. and in some European countries. Some will retire within the next few years and few replacements are currently in training. Whereas adult neuropathologists usually can provide a credible alternative for the diagnosis of brain tumours in children and of some conditions that are similar to those in adults, such as CNS infections and demyelinating diseases, most are neither prepared by training nor motivated by interest to teach developmental neuroanatomy. Moreover, a majority of adult neuropathologists have only sparse knowledge of the embryology of muscle and peripheral nerve to accurately interpret biopsies of these tissues in neonates and young infants with congenital myopathies and developmental neuropathies.

3) Lack of experience of most of the junior paediatric neurology faculty in neuroembryology. Most junior and intermediate faculty members of paediatric neurology training programmes cannot teach neuroembryology because they themselves lacked the experience of such preparation during their own residencies, attesting to the chronicity of the problem. Not only are they unable to instruct their trainees in this discipline, many do not even appreciate its relevance in the overall preparation of residents; their concepts of neuroembryology necessarily remain vague and poorly differentiated. They perpetuate an incomplete training that they themselves suffered because of chronic neglect over decades.

4) Perception that modern neuroimaging can replace or substitute for neuroembryology and neuropathology. Neuroimaging of the immature brain, including fetal cranial ultrasound and MRI, has been a major advance and has contributed much to the precision of diagnosis in the living patient using minimally invasive or noninvasive techniques. Just three decades ago we were limited to invasive angiography, pneumoencephalography and myelography as the only radiological techniques available to visualize the CNS in the living patient. The great limitation of all modern neuroimaging techniques remains, however, that resolution is only as good as the naked eye; none of the present generation of MRI and various techniques of functional imaging is a microscope to directly view individual cells.

This commentary is not intended as a criticism of our radiology colleagues or of clinical neurologists but rather to encourage collaboration. Many of the enlightened leaders in paediatric neuroimaging, such as Drs. Jim Barkovich at UCSF ${ }^{14}$ and Anne Osborn at the University of Utah ${ }^{15}$, are amongst the first to recognize the importance of supplementary anatomical and neuropathological correlations to better understand the images. Regrettably others remain uninformed and consider the features shown by imaging to be the only relevant findings in the diagnosis and interpretation of developmental anomalies. That microscopic diagnosis coupled with modern neuropathological 
techniques is more sensitive than neuroimaging is not a criticism of the great advantages that neuroimaging offers in the living patient or its promise of better resolution in future, but rather is here submitted as a reason why trainees in paediatric neurology require additional exposure to neuroembryology than the gross images of MRI can provide. Gyration and myelination are good examples in normal development that can be well demonstrated by neuroimaging, but only in part. Gyration of normal cerebral cortex is detected in fetal MRI and MRI and CT of prematurely born infants, but imaging only demonstrates the well formed gyri bordered by deep sulci. The more subtle early stages of sulcation that can be seen microscopically before midgestation are invisible to neuroimaging. Myelination is first detected in the corpus callosum at four months postnatally by MRI in T2weighted sequences, but is well seen at two months after term by the traditional luxol fast blue myelin stain in tissue sections, and even earlier by more sensitive neuropathological techniques such as gallocyanin stains and immunoreactivity to myelin basic protein. Individual heterotopic neurons and their synaptic connections cannot be detected by imaging, and the various abnormal neuroblast migratory patterns are only partially revealed by imaging. At times histopathological findings may be suggested in MRI, such as the cytomegalic neurons of the Taylor-type focal cortical dysgenesis, but definitive confirmation remains a microscopic diagnosis in brain tissue surgically resected for intractable epilepsy.

5) Perception that molecular genetic programming of development replaces descriptive morphogenesis and neuroembryology. Remarkable advances have been made in discovering many genes of normal development of the nervous system as well as mutations that cause malformations and neurological disease in the developing brain. Many of the genes involved in radial neuroblast migration are now know, for example, but the listing of such genes and their associations with specific migratory disorders is not a substitute for understanding anatomical patterns and microscopic features. In the classification of cerebral malformations, we have emphasized the need to integrate descriptive morphogenesis with molecular genetics to derive patterns, such as the gradients of genetic expression along the three axes of the neural tube ${ }^{12,13}$.

6) Declining autopsy rate. Postmortem examination provides not only definitive diagnosis or confirmation of the clinical diagnosis, but also is tissue for the study of neuroanatomy including developmental neuroanatomy in the case of immature brain tissue. The autopsy rate has steadily fallen over the past two decades. One reason relates again to the perception that neuroimaging is definitive and nothing more can be gained by tissue examination. A diagnosis of holoprosencephaly can be made by nearly all modalities of neuroimaging, for example, but the many nuances of the gradients of genetic expression, involvement of the dorsal midbrain that leads to aqueductal atresia and involvement of the mesencephalic neural crest tissue that causes abnormal craniofacial development with midfacial hypoplasia, cannot be specified by imaging alone.

A more important reason for the decline in autopsy rate, in the U.S. much more than in Canada, is that in that country the medical insurance industry does not cover postmortem examination and hospital administrators are reluctant to spend any part of their budget on items that do not generate profit. In a medical system that is profit-driven, financial considerations often predominate over those directly related to actual health care. In both Canada and the U.S., autopsy rates of aborted fetuses, whether spontaneous or induced, generally are higher than the general autopsy rates in children and adults, however, in part because parents want to know the reason for fetal loss in terms of genetic or infectious diseases that might increase risk in future pregnancies and in part because the products of conception are legally regarded as surgical tissue specimens rather than autopsies. Whereas a low rate of postmortem examination does negatively impact the teaching of developmental neuroanatomy, it is not the most important factor. Availability of neuropathologists to effectively study fetal brain and the desire of residency programmes to encourage the exposure of residents to these examinations are of greater importance.

7) Paucity of questions about neuroembryology in the Royal College examination in paediatric neurology. One can argue over whether preparing for the Royal College examination should be the focus of a paediatric neurology training progamme, but one cannot deny that it must be one goal if the trainees are to do well and the training programme itself continue to be accredited and that it is a strong motivating force for trainees to learn material upon which they will be examined. If more questions in the Royal College examination were devoted to neuroembryology, trainees would be demanding that it be taught and would be learning more in their independent study. Another important stimulus to neuroembryology teaching that the Royal College could provide would be a requirement that training programmes document the amount of time devoted to this discipline.

\section{Rôle Of Neuropathology In Paediatric Neurology Training Programmes}

Advances in molecular genetics and neuroembryology have demonstrated the intimate relation of neuroembryology to developmental neuropathology, but the aspect of normal development must be mastered before one can understand the pathogenesis of CNS malformations and how acquired lesions of the developing brain, such as infarcts and haemorrhages, can affect its maturation. Even perinatally acquired lesions that are unique in the fetal and neonatal brain, such as periventricular leukomalacia and germinal matrix haemorrhages are largely explained by immaturity of blood vessels and differences in vascular perfusion between immature and mature brain. Congenital infections interfere with developmental processes and lead to acquired malformations best understood in the context of ontogeny. The teaching of neuroembryology must, therefore, be integrated with the teaching of fetal and neonatal neuropathology for more insightful understanding of both.

\section{Royal College Requirements Of Specialty Training In Paediatric Neurology And In Neuropathology}

The Education Committee of the Royal College of Physicians and Surgeons of Canada has published a list of training objectives or requirements. The following excerpts are quoted: 
Paediatric Neurology (2001). "As a basis for clinical competence, the neurologist must be familiar with and able to describe or discuss:

3.3 the embryological development of the nervous system and how congenital anomalies arise from disorders of this process;

3.4 the gross and microscopic anatomy of the nervous system, nerve roots, peripheral nerves, muscles and the vascular system of the nervous system; this includes the recognition of the structures in both anatomical and neuro-imaging formats (when technically feasible);

3.27 the basic histopathological reactions which occur in nervous system disorders;

3.28 the pathological changes (gross and microscopic) occurring in the major neurological diseases..."

Neuropathology (2007). "Establish and maintain clinical knowledge, skills and attitudes appropriate to neuropathology...including:

2.1.2. the embryological, fetal and postnatal development of the nervous system and how congenital anomalies arise from disorders of this process;

2.1.3 the normal gross and light microscopic appearance of tissues of the nervous system..."

It is evident from these statements in the Royal College documents for both paediatric neurology and neuropathology that there are specified expectations of both teaching within programmes and learning and competence by trainees, in the fields of neuroanatomy, neuroembryology and developmental neuropathology with specifically stated emphasis on malformations of the nervous system. The number of examination questions related to developmental neuroanatomy and fetal neuropathology posed by the Royal College, however, is disproportionately small in relation to its stated training objectives.

\section{Realistic Solutions To Address Deficiencies OF Teaching Neuroembryology To Paediatric Neurology RESIDENTS}

1) Acknowledgement of the need. The problem of inadequate instruction in embryology cannot be solved until recognized and acknowledged as a problem. Continuing to ignore or even deny the role and importance of training in neuroembryology in paediatric neurology clinical residencies is an attitude that must be addressed before time runs out to even make incorporating neuroembryology as an option because of the lack of qualified teachers of this discipline. Acceptance of the problem will create the opportunity to address and solve it.

2) Planning for continuous exposure during training years. It is more enduring to the trainees to have exposure to a discipline over the entire period of their training rather than a concentrated month or two during their final year of residency. One expects residents to review the neuroimaging and EEGs of their patients throughout their training, not to limit their exposure to a concentrated elective in neuroradiology and another in clinical neurophysiology. Such focused electives or required rotations also are very useful, particularly because of greater interaction with radiologists and clinical neurophysiologists, but such rotations should supplement rather than replace ongoing exposure. The best way to achieve such ongoing exposure is by regular attendance at gross neuropathology (braincut) sessions conducted by a neuropathologist, ideally a paediatric-oriented neuropathologist. If regular attendance by all residents is not feasible, a rotating schedule could provide time at least once a month for each resident to attend, just as scheduled subspecialty outpatient clinics are preprogrammed. In any paediatric teaching hospital, the overwhelming majority of autopsies are of fetuses and neonates, with occasional older children, providing an excellent opportunity to learn fetal neuroanatomy as well as fetal neuropathology.

3) Supplementary didactic sessions. Presentations by faculty can establish basic principles of development. Additional "slide sessions" to show microscopic features, using glass microscope slides in a multiheaded microscope and/or Powerpoint presentations compliment the braincut sessions from a different perspective. These can be scheduled once every four to six weeks during residents' weekly "academic half-days".

4) Neuroembryology course. An alternative or supplement to the didactic session could be a full-day structured course in neuroembryology. This course would also contrast selected developmental malformations to highlight normal development by comparing it with the abnormal, but a separate course in fetal neuropathology also would be of great value, particularly for acquired lesions of the brain during fetal life.

I am in the process of preparing such courses, complete with Powerpoint presentations, syllabus, microscope slide sets, and the contributions of additional faculty will be sought to offer the course at major medical centres across Canada, as well as a precongressional event or during the course day of the Canadian Neurological Sciences Federation annual meeting. This course will also provide a uniformity or standardization of teaching across Canada. Instructors could include other paediatric neuropathologists in Canada and also some radiologists with special interest and experience in fetal MRI. Not only the target audience of paediatric neurology and neuropathology residents, but also some trainees in adult neurology, neurosurgery, neonatology, radiology, genetics and anatomical pathology also might be interested. Some paediatric neurology junior faculty may wish to fulfill a deficiency during their own training, to enable them to incorporate these unique principles into their own learning and teaching. Such a course also could have appeal to some basic neuroscientists and postgraduate students. The course summarized above eventually also could be published, accompanied by a CD-ROM of figures, for independent study or offered online.

Finally, one must pose the practical question of whether a physician's knowledge or lack of knowledge about embryology in treating children with clinical effects of cerebral malformations influences patient outcome. In the interest of evidence-based medicine, the proposed teaching modules eventually should be formally scrutinized and objectively evaluated in this context of improved patient care. In this context, however, an understanding of disease processes always enhances patient care even if the relation is not always immediately evident. Many examples can be cited in which inappropriate treatment has resulted from lack of knowledge of the embryology. One such example is the placing of a shunt in an infant with colpocephaly associated with agenesis of the corpus callosum or with hemimegalencephaly; an ontogenetic 
understanding of the cause of ventriculomegaly in such cases, which is not due to obstructive hydrocephalus, could avoid invasive and unnecessary treatment ${ }^{16}$. Facial dysmorphism, such as the midfacial hypoplasias of holoprosencephaly, not only denote the type of malformation but tell the clinician about the extent of the rostrocaudal gradient of genetic expression to have reached the mesencephalic neural crest and important implications for neurological deficits at the midbrain level and for prognosis. Many parents desire scientific information about malformations that occur in their infants or fetuses. Physicians with little knowledge of embryology cannot provide such explanations and parents who research the topic on the internet may lose confidence in the physician who does not know the answers to reasonable questions that they pose.

5) Inclusion of more questions on neuroembryology in the Royal College examination for paediatric neurology candidates. Whereas we strive to prepare our trainees to be good neurologists first and not to spend their residency just preparing for the Royal College examination at the end, there remains realism that the prospect of being examined on a topic is a powerful motivating force for study.

\section{Implications For A Broader InTERnATIONAL AUdience}

The decline and current deficiency in teaching neuroembryology is not unique to Canadian institutions. The same history leading to the present state applies equally to most American training programmes and to those of other countries as well. The American Boards of Neurology and Psychiatry and of Neuropathology have clauses similar to those found in the Royal College documents in Canada. Though the proposed course is designed for Canada, it could be broadened in its international appeal.

In the 1970s Drs. Kiffen Penry, a neuropharmacologist at the National Institutes of Health and Fritz ("Fred") E. Dreifuss, neurologist at the University of Virginia in Charlottesville, designed a comprehensive course in epilepsy that not only was the first of its kind in the world, but became a very popular international course and a model for many national courses subsequently designed in various countries. I had the privilege of knowing this course well because I was a resident under the mentorship of Dr. Dreifuss at that time. There is, therefore, a precedent for a similar endeavour in this proposed neuroembryology course that would be a Canadian initiative, but would have a potential for becoming adopted in the U.S.A. and in many other countries.

\section{Conclusions}

Neuroembryology is fundamental in understanding the development of the nervous system. Without this insight, malformations and metabolic diseases cannot be fully comprehended. The reintroduction of structured educational programmes in the ontogenesis of the central and peripheral nervous systems in paediatric neurology and neuropathology residency training programmes in Canada would provide a unique and valuable supplement to resident education and fulfill the mandate of the Royal College. Despite the several reasons for its past reduction from the curriculum, recognition of its importance and relevance can create new opportunities to correct the deficiency if there is a desire and availability of qualified faculty to undertake the responsibility of teaching this aspect of development. A formal course in neuroembryology and fetal neuropathology would be a means to initiate learning of this discipline, and would be of value not only for paediatric neurologists, but also for neuropathologists, adult neurologists, neurosurgeons, neuroradiologists, neonatologists, geneticists and some basic scientists, not only those still in training but also faculty members who did not receive this training or who desire an updated refresher course. This course has a potential for a broader international audience beyond Canada.

\section{REFERENCES}

1. O'Rahilly R, Müller F. The embryonic human brain. An atlas of developmental stages. 3rd ed. New York: Wiley-Liss; 2006.

2. Bayer SA, Altman J. Atlas of human central nervous system development. Vol 1. The spinal cord from gestational week 4 to the 4th postnatal month. Boca Raton, Florida: CRC Press; 2002.

3. Bayer SA, Altman J. Atlas of human central nervous system development. Vol 2. The human brain during the third trimester. Boca Raton, Florida: CRC Press; 2004.

4. Bayer SA, Altman J. Atlas of human central nervous system development. Vol 3. The human brain during the second trimester. Boca Raton, Florida: CRC Press; 2005.

5. Bayer SA, Altman J. Atlas of human central nervous system development. Vol 4. The human brain during the late first trimester. Boca Raton, Florida: CRC Press; 2006.

6. Bayer SA, Altman J. Atlas of human central nervous system development. Vol 5 . The human brain during the early first trimester. Boca Raton, Florida: CRC Press; 2008.

7. Sarnat HB. Cerebral dysgenesis. Embryology and clinical expression. NY, London, Toronto: Oxford University Press; 1992.

8. Norman MG, editor. Congenital malformations of the brain. Pathological, embryological, clinical, radiological and genetic aspects. NY, London, Toronto: Oxford University Press; 1995.

9. Yakovlev PI, Lecours A-R. The myelination cycles of regional maturation of the brain. In: Minkowski A, editor. Regional development of the brain in early life. Philadelphia: FA Davis; 1967. p. 3-70.

10. Rorke L, Riggs E. Myelination of the brain in the newborn. Philadelphia: Lippincott; 1968.

11. Sarnat HB, Flores-Sarnat L. Integrative classification of morphological and molecular genetics in central nervous system malformations. Am J Med Genet. 2004;126A:386-92.

12. Flores-Sarnat L, Sarnat HB. Axes and gradients of the neural tube for a morphological/molecular genetic classification of nervous system malformations. In: Sarnat $\mathrm{HB}$, Curatolo P, editors. Handbook of clinical neurology, Vol. 87 (3rd series): Malformations of the nervous system. Edinburgh, London, NY, Toronto: Elsevier B.V; 2008. p. 3-11.

13. Sarnat HB, Flores-Sarnat L. Synaptogenesis in the human fetal and neonatal brain: 1. Hippocampus and neocortex. J Neuropathol Exp Neurol. [In press 2009].

14. Barkovich AJ, Pediatric Neuroimaging, 4th ed. Philadelphia: Lippincott Williams \& Wilkins; 2005.

15. Osborn AG, Blaser SI, Salzman KL, Katzman GL, Provenzale J, Castillo M, et al. Diagnostic imaging. Brain. Salt Lake City: Amirsys; 2004.

16. Flores-Sarnat L. Hemimegalencephaly. Part 1. Genetic, clinical and imaging aspects. J Child Neurol. 2002;17:373-84. 